\title{
The Effectiveness of Structural Policy in the European Union: An Empirical Analysis for the EU-15 in 1995-2001*
}

\author{
MAAIKE BEUGELSDIJK \\ De Nederlandsche Bank \\ SYLVESTER C.W. EIJFFINGER \\ Tilburg University
}

\begin{abstract}
The main aim of structural policy is to decrease the regional disparities within the European Union (EU). In 2004 ten new member countries joined the EU, and it is expected that this enlargement will cause strong regional disparities within the Union. For this reason the distribution of financial support by structural policy will undergo drastic changes. In this study we consider two main themes. First, convergence of the current EU Member States is empirically tested for the period 19952002, and the effect of the structural funds in this context is identified. Structural funds do indeed appear to have had a positive impact, and poorer countries (like Greece) appear to have caught up with the richer countries. The importance of the structural funds in this respect therefore cannot be neglected. Second, we touch on the problem of moral hazard and the substitution effect. It may be expected that receivers of structural funds in some cases are not really eligible and may therefore use the funds inefficiently. Our first and preliminary results seem to indicate that the less clean countries (or as we measure it, more 'corrupt' countries) of the current EU15 do not gain less economic growth from the structural funds. The hypothesis that structural funds contributed to fewer interregional disparities within the current 15 European countries cannot be rejected. This may mean the intended plans of channelling a big share of the funds to the candidate countries in 2007-13 will probably contribute to higher economic growth in these countries.
\end{abstract}

\footnotetext{
* Empirical research was conducted while Maaike Beugelsdijk had an internship at De Nederlandsche Bank from September 2001 to March 2002. The authors gratefully acknowledge comments from Arthur van Soest (Tilburg University) and Marga Peeters (De Nederlandsche Bank) without implicating them or De Nederlandsche Bank. This article was written before the recent enlargement.
} 


\section{Introduction}

In 1993 the European summit of the European Union (EU) gathered in Copenhagen and made an historical decision that the associated countries in central and eastern Europe (CEECs) were allowed to become EU members if they so wished. Now, more than ten years later, the first group of CEECs has joined the European Union. Enlargement is obviously not an easy process: the new member countries are relatively less wealthy, and have a GDP per capita that is less than the EU average, implying that enlargement means a decline in the average GDP per capita of the Union. Moreover, the candidate countries face a wide range of internal regional problems and are economically and socially behind the established EU members.

A fundamental objective of the EU is cohesion, the reduction of economic and social disparities between richer and poorer regions within the Union. To ensure that this goal is reached, the Treaty introduced the concept of structural funds. It follows that, because of the huge gap between the current EU and accession countries, the structural funds will be channelled in the direction of the accession countries. This means that, without fundamental changes to budgetary and other economic policies, the accession of the candidate countries will cause fundamental financial losses for the present net contributors and beneficiaries of the EU. This may entail economic changes.

Besides these higher fiscal costs for current EU members, other macroeconomic consequences are also significant. In this article we intend to show the possible macroeconomic effects of budgetary policies on the EU-15, a major factor as the next budget period is approaching, a period that will include the expanded Union. First, the broad question we try to answer is whether the funds bring about a convergence effect. Second, potential moral hazard and substitution effect problems in connection with the structural funds are discussed. The likelihood of receiving structural funds may induce countries to change domestic policies such that the receipt of funds is assured. Under these circumstances it might be expected that structural funds are inefficiently used. An attempt is made to analyse the existence and possible consequences of moral hazard.

The remainder of the article is structured as follows. Section I provides an overview of convergence theories. Section II then studies convergence effects empirically in the current EU countries. We estimate different models to investigate whether, in a previous enlargement, poor EU countries caught up and, if so, whether catching up was a result of the structural funds, and whether moral hazard and substitution effects occurred. The final section summarizes and concludes. 


\section{The Theoretical Concept of Convergence}

This article is an attempt to test whether structural policy affects European economies in such a way that poor regions catch up with the rich. Several authors have studied the relation between European structural policy and convergence of the member countries (e.g. Barro and Sala-i-Martin, 1991, 1992; Canova and Marcet, 1995; Canova, 1999; Boldrin and Canova, 2001; CrespoCuaresma et al., 2001). This section reviews the theoretical concept of convergence and the empirical findings. The next subsection explains the often referred to $\beta$ - and $\sigma$-convergence; the following subsection discusses the analyses of Canova (1999), who was most critical of European structural policy. The final subsection summarizes and concludes.

\section{Barro and Sala-i-Martin's Concept of $\beta$-convergence and $\sigma$-convergence}

The first convergence concept discussed here is called $\beta$-convergence as introduced by Barro and Sala-i-Martin (BS) $(1991,1992)$. It is said that $\beta$-convergence occurs where there is a negative correlation between initial levels of real GDP per capita and its average annual growth rate. Conditional $\beta$-convergence takes place where the negative relationship still holds after controlling for other variables. Intuitively this implies the following. If a country starts with a lower income per capita compared to the average, it can have a higher income relative to other countries after $\mathrm{T}$ periods. In this case it catches up. To test whether poorer countries grow more quickly after controlling for certain observed variables simply implies adding other country- and timespecific variables to the equation.

Barro and Sala-i-Martin used a neoclassical framework that can be split into conditional and unconditional convergence. The regression equation considered for the unconditional convergence is as follows:

$$
\left(1 n y_{T i}-1 n y_{0, i}\right) / n_{t}=\alpha+\beta 1 n y_{t i}+\varepsilon_{t i}
$$

where $y_{t i}$ represents each country's per capita income relative to the aggregate per capita income over all countries at each time $t, T$ is the number of years run, $n_{t}$ is the number of periods considered, $\alpha, \beta$ are parameters to be estimated and $\varepsilon_{t i}$ is a disturbance term that is independently and identically distributed.

$\mathrm{BS}$ also used another convergence concept which is called $\sigma$-convergence. This concept is about the various measures of dispersion or variation in the distribution of per capita income at time T. Conditional $\sigma$-convergence applies if the value of $\log \left(y_{t, i}\right)-\log y_{i}^{*}$ declines over time, where $y_{i}^{*}$ represents the steady state level. 
The difference between the two types of convergence is the following. In cases where the speed and extent of the catching up of per capita income of a particular economy to the average of per capita incomes across economies is of relevance, $\beta$-convergence is the appropriate concept. However, in cases where the interest concerns the development of the distribution of per capita income across economies, $\sigma$-convergence is significant. Evidently, $\beta$-convergence is a necessary but insufficient condition for $\sigma$-convergence. A positive $\beta$ tends to reduce the dispersion of per capita income but another new shock is able to widen the gap between the steady state and the 'current' per capita income. Hence, in cases where there is no $\beta$-convergence but divergence, it is not possible to have $\sigma$-convergence.

\section{European Convergence According to Canova and Others}

According to most studies, like Barro and Sala-i-Martin, differences in per capita income between economic areas will slowly disappear as time goes by, as long as countries follow 'adequate' policies on, e.g., human capital accumulation and the size of the government sector. They analyse the available data with cross-section regressions. Canova's findings are the opposite of those by BS for the unconditional convergence of 2 per cent per year across Europe and the US. In Canova and Marcet (1995), a model specification is used that is consistent with the standard neoclassical growth model. The only difference is that they provide an alternative definition of convergence that allows them to analyse the evolution over time of per capita income. They propose a Bayesian procedure ${ }^{1}$ to estimate convergence rates and steady states, and use the available information for all periods and all cross-sectional units. The crucial distinction between the neoclassical approach and the approach taken by Canova and Marcet is the fact that the latter authors have dropped the assumption that the steady states are the same across countries.

Canova and Marcet studied income convergence across countries and regions, implying that they used different sizes of economies in their study. Their study shows that the average estimates of the convergence rate are much higher than in other studies and that each unit converges to its own steady state. Another major finding is the fact that the initial income conditions are by far the most important determinant of the cross-sectional dispersion of steady states. This means that poor regions and/or countries stay poor as their steady-state level is lower than that of a rich region.

In other words, they conclude that high convergence rates exist but, as there are different levels of steady states, inequalities largely continue to exist. Consequently, they suggest that current redistribution and development

\footnotetext{
${ }^{1}$ They impose a Bayesian prior on the parameters and combine it with the sample information to construct posterior estimates. For more information, see Canova and Marcet (1995) and Berger (1985).
}

(C) Blackwell Publishing Ltd 2005 
policies, such as the EU structural policy, may not fully work. Poor regions can only become as well off as the rich ones if structural changes occur in the economic environment.

In addition to this divergence effect, Canova (1999) found that, within each country, rich regions grow more quickly than poor ones and the rich regions of poor countries grow more quickly than those regions in 'above average' countries. This effect might result in 'convergence clubs'. Convergence clubs imply that above average regions tend to cluster around another pole of attraction than the less developed regions. Canova (1999) examined whether it is the distribution of per capita income that displays these convergence clubs. He found that the dispersion of steady states around each attraction base is significant. This implies that it is more obvious to expect group or club formation instead of a convergence process of the poor regions. He concluded that four different convergence clubs will emerge in the long run, with the very rich and the very poor located far away from the EU average.

Given this result, Canova has tested whether EU policies, such as structural policies, have any impact on the income disparities between countries and regions (Boldrin and Canova, 2001). Are those policies reducing the gap between the rich and poor?

Boldrin and Canova investigated the behaviour of the distribution of the regional per capita income for the period 1980-96. A number of results emerged. First, in 1996, there is still no real tendency for the regional per capita income to grow to their central base of attraction. Second, the gap between the upper and the lower part of the distribution did not really change over time, which means that there is no proof of systematic catching-up of poor regions. Third, only Spain, from the southern countries, shows a small decline in regional income inequalities. Finally, it was shown that some regions within the rich countries became less rich.

Building on the above results, Boldrin and Canova checked whether regions benefit from EU subsidies. They focus their attention on labour productivity and total factor productivity (TFP) to find an explanation for the result of using structural funds. If structural funds are effective in reducing regional differences, TFP and labour productivity of the receiving regions should react positively to the variance in the received amount of structural funds. Subsidies may be spent on, e.g., training and infrastructure which in turn raise labour productivity. It is said that, if average labour productivity of the poorer regions increases, the attraction of private investment may expand, generating employment opportunities and increasing the per capita income in the long run. 
Boldrin and Canova show that there is a small tendency to convergence for labour productivity. As far as TFP is concerned, the variation across regions and over time is large, but has little relation to the flows of structural funds.

\section{Conclusion}

Barro and Sala-i-Martin $(1991,1992)$ found evidence for convergence in general. Canova and Marcet (1995) and, for example, Crespo-Cuaresma et al. (2001) investigated convergence in the EU countries in particular. Canova (1999) is somewhat negative on convergence within the EU. With respect to structural funds, he even argues that 'rich regions can be taxed more heavily for solidarity reasons but not in the hope that these transfers will foster development of the poor regions' (p. 22). On the other hand, the findings of CrespoCuaresma et al. are positive. They conclude that EU membership has a convergence-stimulating effect on long-term growth. In this article we study convergence within the EU and the role of structural funds specifically.

\section{Empirical Research}

In this section we investigate empirically whether there is evidence of convergence in the current EU countries. The role of structural funds is considered in this context. An issue that further arises in the context of structural funds is the potential presence of moral hazard. Regions receive EU funds (such as cohesion funds) only below a certain welfare level. The elite may be inclined not to raise their welfare or manipulate the statistics if their welfare level is around the critical level, as this would possibly imply a reduction in future financial EU support. In other words, it might be possible that the resources are not used on projects that would have the largest direct and indirect impact. This moral hazard effect might lead to an inappropriate use of structural funds. Another effect that might arise is the 'substitution' effect. If a country already had plans to invest in A and the country receives EU money, it may finance plan A through the additional funds, thereby resulting in a crowding-out effect. In order to analyse these convergence, structural funds, moral hazard and substitution effects, panel analyses of the current EU-15 countries are presented and discussed.

The outline is as follows. The first subsection goes into the details of the data. The second presents the econometric models that are estimated; the third presents the econometric results. The last subsection summarizes and concludes. 


\section{Data Issues}

Most annual data covering the period 1984-2002 for current EU countries are extracted from NiGEM. ${ }^{2}$ Preliminary regressions were also carried out for the accession countries (though estimation results are not further presented here). Table 1 reports the data used here and the mean and standard deviation of the main variables used in the econometric analyses.

\section{Econometric Models}

In order to test for convergence, the concept of Crespo-Cuaresma et al. (2001) was used first. Crespo-Cuaresma et al. used a subperiod panel where data are split into four periods, namely 1961-70, 1971-80, 1981-90 and 1991-98. They distinguished these four periods because a minimum number of five to ten years seemed reasonable for studying medium to long-term growth features. Our experience with this 'fixed effects subperiod' model was that the error terms correlate highly with the explanatory variables. For this reason we use the GMM model in our research instead. GMM estimators use more orthogonality conditions and take the covariance structure of the disturbances

Table 1: Descriptive Statistics in Case of Annual Panel EU-15

\begin{tabular}{llcc}
\hline & & Mean & $\begin{array}{c}\text { Standard } \\
\text { Deviation }\end{array}$ \\
\hline GDPgrowth & Annual GDP growth & 0.035 & 0.062 \\
GcRate & Government consumption as part of GDP & 0.209 & 0.036 \\
GiRate & Government investment as part of GDP & 0.028 & 0.008 \\
InfRate & Inflation rate & 0.045 & 0.039 \\
LnGdppc & Natural logarithm of GPD per capita & 8.534 & 0.385 \\
PsiRate & Private-sector investment as part of GDP & 0.171 & 0.023 \\
R3mRate & Three-month interest rate & 0.056 & 0.026 \\
SFRate & Structural funds as part of GDP & 0.007 & 0.025 \\
CorruptionIndex & Index relating the perceptions of the & & \\
& degree of corruption as seen by business & & \\
& people, risk analysts and the general & & \\
public, ranging from 10 (highly & 7.420 & 1.750 \\
CorruptionSFRate & Corruption index multiplied by the SFRate & 0.039 & 0.150 \\
YearEu & No. of years a country is an EU member & 18.260 & 14.360 \\
\hline
\end{tabular}

Source: Authors' own data.

${ }^{2}$ The macroeconometric multi-country world model developed by the National Institute of Economic and Social Research. 
into account. Further, we no longer distinguish four subperiods but take the individual annual data.

The first model we estimate by GMM for the current EU countries for the period 1995-2001 is specified as follows:

$$
\text { GDPgrowth }_{i, t}=\beta_{0}+\beta_{1} \text { GDPgrowth }_{i, t-1}+\beta_{2} \text { GDPgrowth }_{i, t-2}+\beta_{3} \text { lny }_{i, t-1}+u_{i, t}
$$

GDP growth is explained by its growth one and two years in the past and the initial GDP. The $\beta$ s are parameters to be estimated, $u$ is a disturbance term, subscript $i$ indicates the country (so $i$ ranges from 1 to 15 ) and $t$ time. In order to achieve $\beta$-convergence, $\beta_{3}$ should be negative.

In the following regression more explanatory variables are included to study the determinants of growth. Several variables were added, but the econometric specification of the model presented below is:

$$
\begin{aligned}
\text { GDPgrowth }_{i, t} & =\beta_{0}+\beta_{1} \text { GDPgrowth }_{i, t-1}+\beta_{2} \text { GDPgrowth }_{i, t-2}+\beta_{3} \text { lny }_{i, t-1} \\
& +\beta_{4} \text { GcRate }_{i, t-1}+\beta_{5} \text { R3MRate }_{i, t}+\beta_{6} \text { PsiRate }_{i, t-2}+u_{i, t}
\end{aligned}
$$

In order to find out whether structural funds have made a significant contribution to GDP growth we also include these funds in the regression:

$$
\begin{aligned}
\text { GDPgrowth }_{i, t} & =\beta_{0}+\beta_{1} \text { GDPgrowth }_{i, t-1}+\beta_{2} \text { GDPgrowth }_{i, t-2}+\beta_{3} \text { lny }_{i, t-1} \\
& +\beta_{4} \text { SFRate }_{i, t-3}+u_{i, t}
\end{aligned}
$$

An interesting and important issue that arises when considering the impact of structural funds is the potential presence of moral hazard and substitution effects. Testing for these effects is, of course, difficult. We argue that there are two ways to find out whether they influence the growth effect of the structural funds. Firstly, two different regressions could be analysed, one for 'clean' and one for '(highly) corrupt' countries. Clean countries use structural funds in a proper way and corrupt countries use the funds for purposes other than their (EU-defined) intended purposes. A clean country would thus have a different impact on their growth from a corrupt country. To explain it in econometric terms, we can define the relations as:

GDPgrowth $_{i, t}=\beta_{0}+\beta_{1}$ StructuralFunds $_{i, t}+\mathrm{u}_{i, t}$ for 'clean' countries GDPgrowth $_{i, t}=\gamma_{0}+\gamma_{1}$ StructuralFunds $_{i, t}+\mathrm{u}_{i, t}$ for 'corrupt' countries

The constant term for the clean countries is assumed to be larger than that for the corrupt countries so $\beta 0>\gamma 0$, because it represents everything (apart from structural funds) that affects growth. It is thus expected that the more corrup- 
tion occurs within a country, the more moral hazard and substitution negatively influence growth.

In order tentatively to test for the influence of moral hazard and substitution in combination with structural funds, the corruption index is used. The corruption variable varies over time. As explained above, it relates to perceptions of the degree of corruption as seen by business people, risk analysts and the general public, and ranges from 10 (highly clean) to 0 (highly corrupt). So, the higher the index the less corrupt a country.

Finally, an interaction term (see Aiken and West, 1991) can be added to the model to test the explicit hypothesis that corruption controls the effect of structural funds on growth. That is, while the structural funds that a country receives are positively related to the country's growth level, the strength of this relationship may change if the corruption level increases. Expectations are that the relationship is weakened by the interaction term; the more corrupt a country is, the less impact the structural funds have on growth. The final extension of the general model is defined as:

$$
\begin{aligned}
\text { GDPgrowth }_{i, t} & =\beta_{0}+\beta_{1} \text { GDPgrowth }_{i, t-1}+\beta_{2} \text { GDPgrowth }_{i, t-2}+\beta_{3} \text { lny }_{i, t-1} \\
& +\beta_{4} \mathrm{SF}_{i, t-3}+\beta_{5} \text { Corruption SFRate }_{i, t-3}+\beta_{6} \text { CorruptionIndex }_{i, t}+\mathrm{u}_{i, t}
\end{aligned}
$$

The higher the corruption index, the lower the corruption in a country. So, one might expect that in cases where corruption matters, $\beta_{5}$ and $\beta_{6}$ have positive signs.

\section{Empirical Results of the GMM Model}

Tables 2-5 present the GMM estimation results for the panel regression of the 15 current EU countries for the period 1995-2001 of the four models specified and discussed in the previous subsection.

In the following, $\beta$-convergence within the EU is investigated. In cases of $\beta$-convergence, the relatively poorer countries catch up with the relatively richer countries. One may expect that financial help from the EU, the EU structural funds, to these poorer countries have a positive effect on economic growth. This result would contradict Canova's findings, but would be in line with those of Crespo-Cuaresma et al. (2001). Furthermore, we investigate here what happens if some specific countries are excluded from the sample.

Table 2 presents the results of the basic model where only GDP and GDP growth are included. The first and second columns show the one- and twostep GMM estimates, respectively. It follows that the total effect of the initial GDP per capita is significantly negative in both cases. This can be interpreted as evidence that $\beta$-convergence exists. The two-step estimator tends to have a large efficiency gain. So, the fact that the first-step estimates are significant is 
Table 2: GMM Results for EU-15

Explanatory Variables

One-Step Estimation

Two-Step Estimation

\begin{tabular}{lrrrr}
\hline Constant & 0.03 & $(0.01)$ & 0.03 & $(0.00)$ \\
$\Delta$ Growth $_{i, t-1}$ & -0.09 & $(0.25)$ & -0.01 & $(0.08)$ \\
$\Delta$ Growth $_{i, t-2}$ & -1.73 & $(0.83)$ & -1.83 & $(0.17)$ \\
$\Delta$ Ln y $_{i, t-1}$ & -0.56 & $(0.25)$ & -0.54 & $(0.07)$ \\
Sargan test & & 0.00 & & 0.84 \\
Arellano-Bond test of order 1 & 0.00 & & 0.16 \\
Arellano-Bond test of order 2 & & 0.18 & & 0.36
\end{tabular}

Source: Authors' own data.

Notes: Figures within brackets are standard errors. P-values are shown for the Sargan and Arellano-Bond tests. The added variable is $\ln$ GDPpc.

sufficient for having significant two-step estimates. The Sargan test investigates over-identified restrictions (see Arellano and Bond, 1991). Under the $\mathrm{H}_{0}$-hypothesis the instruments are valid. Rejection of the Sargan test can be evidence that the (instrumental) variables might not have been exogenous. While the coefficients of the two regressions are almost the same, the regressions in Table 2 show that with the one-step estimator the null hypothesis is

Table 3: GMM Estimation Results for EU-15 with Additional Variables

\begin{tabular}{lrlrl}
\hline Explanatory Variables & One-Step & Estimation & Two-Step Estimation \\
\hline Constant & 0.02 & $(0.01)$ & 0.02 & $(0.00)$ \\
$\Delta$ Growth $_{i, t-1}$ & 0.04 & $(0.28)$ & 0.38 & $(0.20)$ \\
Growth $_{i, t-2}$ & -1.74 & $(0.86)$ & -0.64 & $(0.57)$ \\
$\Delta$ Ln y $_{i, t-1}$ & -0.59 & $(0.28)$ & -0.99 & $(0.23)$ \\
$\Delta$ GcRate $_{i, t-1}$ & -0.96 & $(2.46)$ & -2.60 & $(1.28)$ \\
$\Delta$ R3MRate $_{i, t}$ & 1.47 & $(0.76)$ & 0.36 & $(0.49)$ \\
$\Delta$ PsiRate $_{i, t-2}$ & 2.06 & $(1.32)$ & 1.93 & $(0.39)$ \\
Sargan test $_{\text {Arellano-Bond test of order 1 }}$ & & 0.00 & & 1.00 \\
Arellano-Bond test of order 2 & & 0.73 & & 0.22 \\
\hline
\end{tabular}

Source: Authors' own data.

Notes: Figures within brackets are standard errors. P-values are shown for the Sargan and Arellano-Bond tests. Additional instrumental variables are $\ln$ GDPpc, YearEu, InfRate, r3mrate(-1), GiRate(-2), GcRate and PsiRate, PsiRate(-1).

(C) Blackwell Publishing Ltd 2005 
Table 4: GMM Estimation Results Including Structural Funds

\begin{tabular}{lrlrl}
\hline Explanatory Variables & One-Step Estimation & Two-Step Estimation \\
\hline Constant & 0.03 & $(0.01)$ & 0.03 & $(0.00)$ \\
$\Delta$ Growth $_{i, t-1}$ & 0.16 & $(0.37)$ & 0.10 & $(0.07)$ \\
$\Delta$ Growth $_{i, t-2}$ & -2.19 & $(1.03)$ & -1.68 & $(0.46)$ \\
$\Delta$ Ln y $_{i, t-1}$ & -0.71 & $(0.37)$ & -0.65 & $(0.09)$ \\
$\Delta$ SFRate $_{i, t-3}$ & 0.27 & $(0.85)$ & 0.32 & $(0.10)$ \\
Sargan test $_{\text {Arellano-Bond test of order 1 }}$ & & 0.02 & & 0.97 \\
Arellano-Bond test of order 2 & & 0.00 & & 0.16 \\
\hline
\end{tabular}

Source: Authors' own data.

Notes: Figures in brackets are standard errors. P-values are shown for the Sargan and Arellano-Bond tests. Additional instrumental variables are YearEu, SFRate, ln GDPpc.

rejected and the two-step estimator is accepted. According to the ArellanoBond tests, there is no serious autocorrelation.

The estimation results for the first extension of the general model are presented in Table 3. Government consumption, the short-term interest rate and private-sector investment are included. The signs of the coefficients for initial GDP per capita are negative and significant, so $\beta$-convergence is not rejected. Government consumption is significantly negative in the two-step estimation. This negative sign implies that there is a negative relationship between government consumption and growth. This may indicate that higher debt levels occurring through excessive government spending damage growth and bureaucracy. The private-sector investment rate, as expected, adds positively to growth.

The Sargan test in the two-step estimation method is precisely 1 . This is an indication that there are too many instrumental variables. However, this has no serious implications for the estimation result.

In a second extension of the general model, structural funds are included. Table 4 shows that, in both the one-step and the two-step estimation models, the poorer countries catch up with the rich. The one-step estimator gives an insignificant coefficient for the impact of the structural policy on economic growth. But the two-step estimator shows a significant positive sign. According to these results, structural funds policy has a positive impact on growth three years ahead. One might say that if the change in the rate between the structural funds and the GDP changes by 1 percentage point, the GDP growth will increase by a 0.32 percentage point in the case of the two-step estimation method. 
In the models so far, only the full sample of EU-15 countries is considered. It is also interesting to obtain some insights into the individual countries. For this purpose we first eliminate Greece from the sample. One would expect that the catching-up effect of the other 14 EU countries would decrease. The estimation results - not shown here - indicate that the one- and two-step estimations for the convergence parameter are smaller (and significant). So, Greece does indeed seem to catch up strongly with the richer countries.

Finally, we test for moral hazard and substitution effects as explained in the previous subsection. Table 5 presents the GMM estimation results for including the corruption index and the interaction term of corruption and structural policy. Both added variables turn out to be insignificant in both estimation procedures. So, on the basis of these results, one cannot conclude that for the more corrupt countries, the relationship of structural funds to growth is weaker.

\section{Summary of Econometric Results}

Econometric models were estimated to analyse whether there has been a convergence of the poorer with the richer countries within the European Union. The estimation results show that convergence does indeed occur, so there is so-called $\beta$-convergence. Even the one-step estimation results appear to confirm this. Also, the inclusion of additional explanatory macroeconomic vari-

Table 5: GMM Estimations Results Including Structural Funds and Corruption Index

\begin{tabular}{lrlrl}
\hline Explanatory Variables & One-Step Estimation & Two-Step Estimation \\
\hline Constant & 0.05 & $(0.01)$ & 0.03 & $(0.01)$ \\
$\Delta$ Growth $_{i, t-1}$ & 0.41 & $(0.41)$ & 0.14 & $(0.21)$ \\
$\Delta_{\text {Growth }}$ & -2.38 & $(1.04)$ & -2.19 & $(0.82)$ \\
$\Delta$ Ln y $_{i, t-1}$ & -0.97 & $(0.42)$ & -0.67 & $(0.26)$ \\
$\Delta$ SFRate $_{i, t-3}$ & 16.08 & $(9.93)$ & 4.04 & $(7.10)$ \\
$\Delta$ CorruptionSFRate $_{i, t-3}$ & -2.36 & $(1.48)$ & -0.57 & $(1.06)$ \\
$\Delta$ CorruptionIndex $_{i, t}$ & -0.03 & $(0.06)$ & -0.02 & $(0.02)$ \\
Sargan test $_{\text {Arellano-Bond test of order 1 }}$ & & 0.04 & & 0.99 \\
Arellano-Bond test of order 2 & & 0.12 & & 0.13 \\
\hline
\end{tabular}

Source: Authors' own data.

Notes: Figures in brackets are standard errors. P-values are shown for the Sargan and Arellano-Bond tests. Additional instrumental variables are YearEu, SFRate, ln GDPpc.

(C) Blackwell Publishing Ltd 2005 
ables does not lead to a rejection of the hypothesis of this catching-up process. The private-sector investment rate has a positive impact on economic growth (see Levine and Renelt, 1992). Government consumption appears to have a negative effect on growth, implying that debt levels appear to damage growth and bureaucracy.

However, the aim of this article is to investigate the potential impact of the structural funds. Inclusion of the funds does not change the signs of the variables in the general model. So, we can still speak of $\beta$-convergence. Countries receiving funds catch up with rich countries. These findings are in line with those of Crespo-Cuaresma et al. (2001), but contradict the findings of Canova and Marcet (1995), who critically assessed the structural policy of the European Union.

In order to gain more insights some countries were excluded from the data set. Greece, for instance, was consecutively excluded. Here, the $\beta$-convergence coefficient becomes lower, indicating that Greece seems to catch up quickly with the richer EU countries.

The issue of moral hazard and the substitution effect is intriguing. Moral hazard may occur if an EU country does not invest in certain regions with the purpose of keeping the welfare level low, while the substitution effect may occur when no additional investments take place but the planned investments are paid with the received funds. Funds from the EU would therefore be received in an inappropriate way. This moral hazard effect is clearly difficult to test, as it is not easy to measure and identify. It may happen at the regional level and is hard to disentangle from other (unforeseen) types of inefficient use of funds. In order to test it tentatively, a corruption index is included in the regressions that aims to represent the corruption level of a country. The results do not seem to indicate that the more corrupt countries use their structural funds in a more inefficient way.

\section{Conclusions}

The main aim of structural policy is to decrease regional disparities within the European Union. On 1 May 2004 ten new member countries joined the EU (Cyprus, Czech Republic, Estonia, Hungary, Latvia, Lithuania, Malta, Poland, Slovak Republic, Slovenia) and Bulgaria and Romania are waiting in line too. It was expected that this enlargement would cause strong regional disparities within the Union. For this reason the distribution of financial support by the structural policy may undergo drastic changes. The current members of the Union will become net contributors to the funds, whereas the candidate countries will become net receivers. For this reason it is important to know the impact of the structural funds. 
In this study we considered two main themes. First, convergence of the current EU member countries was empirically tested for the period 19952002, and the effect of the structural funds in this context was identified. Structural funds may indeed have had a positive impact, and poorer countries (like Greece) seem to have caught up with the richer countries. The importance of the structural funds in this respect therefore cannot be neglected. Second, we touched on the problems of moral hazard and the substitution effect. It may be expected that receivers of structural funds in some cases are not really eligible and may therefore use the funds inefficiently. Our first and preliminary results appear to indicate that the less clean countries (or as we measure it, more corrupt countries) of the current EU-15 do not gain less economic growth from the structural funds.

General though tentative conclusions that we would like to draw from the analyses are the following. The hypothesis that structural funds contributed to fewer interregional disparities within the current 15 European countries cannot be rejected. For this reason we take the view, in contrast to Canova and Marcet (1995), that continuation of the structural policy is to be encouraged. This may mean that the intended plans of channelling a big share of the funds to the candidate countries in 2007-13 will probably contribute to higher economic growth in these countries. The results in this article do not indicate that the more corrupt countries use their structural funds in a more inefficient way.

Correspondence:

Maaike Beugelsdijk

Ruysdaelkade 269 c

Sylvester C.W. Eijffinger

1072 AZ Amsterdam

CentER, Tilburg University

P.O.Box 90153

The Netherlands

Tel: +3 1207719261

5000 LE Tilburg

The Netherlands

email: maaikebeugelsdijk@ raketnet.nl

Tel: +3 113 4662416/2411

Fax: +3 1134663042

email: s.c.w.eijffinger@uvt.nl

\section{References}

Aiken, L.S. and West, S.G. (1991) Multiple Regression: Testing and Interpreting Interactions (London: Sage).

Arellano, M. and Bond, S. (1991) 'Some Tests of Specification for Panel Data: Monte Carlo Evidence and an Application to Employment Equations'. Review of Economic Studies, No. 58, pp. 277-97.

Barro, R.J. and Sala-I-Martin, X. (1991) 'Convergence across States and Regions'. Brookings Papers on Economic Activity, No. 1, pp. 277-97. 
Barro, R.J. and Sala-I-Martin, X. (1992) 'Convergence'. Journal of Political Econo$m y$, Vol. 100, No. 2, pp. 223-51.

Berger, J.O. (1985) Statistical Decision Theory: Foundations, Concepts \& Methods. 2nd edn (New York: Springer Verlag).

Boldrin, M. and Canova, F. (2001) 'Europe's Regions. Income Disparities and Regional Policies'. Economic Policy, April, pp. 207-53.

Canova, F. (1999) 'Testing for Convergence Clubs in Income per Capita: A Predictive Density Approach'. Discussion Paper No. 2201 (London: CEPR).

Canova, F. and Marcet, A. (1995) 'The Poor Stay Poor: Non-convergence across Countries and Regions'. Discussion Paper No.1265 (London: CEPR).

Crespo-Cuaresma, J., Dimitz, M.A. and Ritzberger-Grünwald, D. (2001) 'Growth, Convergence and EU Membership'. Österreichische Nationalbank, presented at East-West Conference November.

Levine, R. and Renelt, D. (1992) 'A Sensitivity Analysis of Cross-country Growth Regressions'. American Economic Review, Vol. 82, No. 4, pp. 942-63.

National Institute of Economic and Social Research (2002) 'NiGEM: The Macroeconometric Multi-country Model'. January 2002 version (London NIESR). 